\title{
Erratum to: Timing, prevalence, determinants and outcomes of homelessness among patients admitted to acute psychiatric wards
}

\author{
Alex D. Tulloch $\cdot$ Paul Fearon $\cdot$ Anthony S. David
}

Published online: 18 August 2011

(C) Springer-Verlag 2011

\section{Erratum to: Soc Psychiatry Psychiatr Epidemiol}

DOI 10.1007/s00127-011-0414-4

In the original publication of this article, there was an error in the calculation of category-based estimates for the effect of age bands on the odds of homelessness, leading to an overestimation of the estimated odds ratio of each ageband relative to the baseline ageband (56-65 years).

In Table 2 the odds ratio and $95 \%$ confidence interval for age 16-25 years should be $2.9(2.1,4.1)$; for age $26-35$ years, it should be $2.2(1.7,2.9)$; for age $36-45$ it should be $1.7(1.4,2.0)$; and for age $46-55$ it should be 1.3 $(1.2,1.4)$. Although the odds of homelessness do decline with age and the level of statistical significance is as described $(p<0.0001)$, the rate of decline cannot be described as 'steep', as in the original Results section.

The online version of the original article can be found under doi:10.1007/s00127-011-0414-4.

A. D. Tulloch $(\square) \cdot$ P. Fearon · A. S. David Department of Psychosis Studies, Institute of Psychiatry,

Kings College London, De Crespigny Park,

London SE5 8AF, UK

e-mail: alex.tulloch@kcl.ac.uk

A. S. David

e-mail: anthony.david@kcl.ac.uk

P. Fearon

Trinity College Dublin and St Patrick's University Hospital,

James's Street, Dublin 8, Ireland

e-mail: pfearon@tcd.ie 